\title{
Necrològica Alicia Rodríguez de Nicol
}

El 21 de febrer de 2018 morí a Mèxic Alicia Rodríguez Chapa. Nascuda en aquella ciutat el 1929, era la vídua d'Eduard Nicol (Barcelona, 1907 - Mèxic, 1990). Es van conèixer a les classes d'Història de la Psicologia que el filòsof impartia a la Universitat Nacional Autònoma de Mèxic (UNAM) durant el curs 1947-1948, però no va ser fins més tard que es van tractar personalment. L'any 1953 els casà el sacerdot i filòsof — també exiliat republicà espanyolJosé Manuel Gallegos Rocafull.

Mort Nicol, tingué cura de les reedicions de la seva obra vigilant-ne les reedicions dels llibres (sobretot els publicats pel Fondo de Cultura Económica). Promogué les iniciatives que sorgiren de recollir en volums els textos dispersos: els papers filosòfics (Símbolo y verdad, Mèxic, 2007) i els articles i assaigs (Las ideas y los días. Artículos e inéditos 1939-1989, Mèxic, 2007).

Es desplaçà a Barcelona per participar en l'homenatge que organitzà la Fundació Acta a la ciutat de naixement del seu marit, pocs mesos després que aquest morís, el 1990. Col-laborà en el monogràfic que la revista Anthropos dedicà al filòsof, amb un text que fixa dades i que explica detalls que rarament haurien transcendit d'una altra manera, vista la proverbial discreció de Nicol en aquest aspecte.

El 1990 signà uns protocols per fer donació d'una part de l'arxiu de Nicol —bàsicament l'epistolari- al Centre d'Història Contemporània de Catalunya (CHCC), que llavors dirigia Josep Benet. Però un dels corresponsals del carteig amb el filòsof protestà a la vídua per aquesta «ingerència en la seva intimitat», tot i que sabia que no seria de consulta pública fins després d'un llarg període de temps. Això desmuntà la donació i la retirada de la primera documentació. Exactament vint anys després, el 2010, aquesta donació es féu efectiva, d'una manera compartida, entre l'Arxiu Històric de la UNAM i l'espanyol CSIC. S'hi poden consultar els originals o les còpies digitalitzades d'originals de textos, de les actes dels seminaris i d'esborranys i escrits inèdits, a més d'una variada documentació personal, inclosa la correspondència. La biblioteca personal del filòsof va ser donada per la vídua a l'Institut d'Investigacions Filològiques de la UNAM. 
Escrits: Àngel CastiN̂neIra (ed.) (1991), «Paraules d'Alicia Rodríguez Chapa», a: Eduard Nicol: Semblança d'un filòsof, Barcelona, Quaderns Acta, 39-40, i Alicia R. de Nicol (1998), «Eduardo Nicol: La vocación cumplida», a: «Eduardo Nicol: La filosofía como razón simbòlica», Anthropos, extra 3, 46-55.

Antoni Mora 